\title{
Critical Analysis of Non-communicable Diseases Community-Based Prevention Model
}

\author{
Sri Handayani* and Diyan Ermawan Effendi \\ Center for Humanities and Health Management, National Institute of Health Research and Development, \\ Ministry of Health of Indonesia, Indonesia
}

\begin{abstract}
National Institute of Health Research and Development of Indonesia had implemented Noncommunicable Diseases (NCDs), a community-based prevention model, in 2015. The objective of this model is to control NCDs such as hypertension, stroke, diabetes, coronary heart by community empowerment. This paper aims to analyze the design of the model critically based on the result of the implementation in Benda village, Sukabumi Regency. Qualitative research had been conducted to assess the successes and challenges of NCDs prevention model in Benda Village, Sukabumi Regency, West Java Province, Indonesia, in 2017. An in-depth interview had used as the primary method to gain data. For the result of this study, NCDs community-based prevention model enabled healthy lifestyle behavior change only on an individual level, not at the society level. NCDs model had not noticed about the influence of social context on behavior change. As a result, the behavior changes that occur were temporary and not sustained. Agents of change also have difficulties in motivating other people to do a healthy lifestyle due to a lack of villager trust in them. NCDs prevention model also had not implemented by following the bottom-up principles in community development. The initiative of this model had not come from the community itself. In conclusion, the NCDs prevention model must consider the social context to achieve healthy lifestyle changes in the community. A holistic and integrated approach can be utilized to improve the design of the NCDs prevention model.
\end{abstract}

Keywords: Community empowerment, Non-communicable diseases, Agents of change

\section{Background}

Non-communicable diseases (NCDs) became the leading cause of death of Indonesian people. 18,78 \% of Indonesian people die because of stroke. The cause of death in ischemic heart disease was about 14,29\%, and $5,91 \%$ of Indonesian people die because of diabetes (IHME, 2019). NCDs prevalence among Indonesian people is also increasing every year. Based on Indonesia Basic Health Survey (2018), the prevalence of stroke based on physician diagnosis has reached $10,9 \%$. Diabetes prevalence based on a blood test is about $10,9 \%$. Heart prevalence based on the physician is about 1,5\%. Hypertension prevalence based on the test between respondents who ages $\geq 18$ years old is $34,1 \%$ (NIHRD, 2018, p.125-166).

Some risky behavior can cause NCDs such as smoking, less physical activity, non-healthy eating food, and alcohol drink consumption. NCDs is a degenerative disease in which people did not realize the symptom in the beginning. Therefore only fewer people have an awareness that they need to go to health facilities to do early NCDs detection (Data Center and Information Ministry of Health of Indonesia, 2012).

Since 2007, to prevent NCDs, the Ministry of Health of Indonesia held the Posbindu PTM program. This program tries to involve people's participation to have an awareness of early detection of NCDs (Ministry of Health of Indonesia, 2007). In reality, the Posbindu PTM program did not work well. From 10.000 Posbindu PTM, only 6000 were active (Kompas, 2015). 
To solve the problem of NCDs, National Health Research and Development, the Ministry of Health of Indonesia had developed an NCDs community-based prevention model in 2014. This model has an objective to control some NCDs such as hypertension, stroke, diabetes, and coronary heart. This model held with the community empowerment method by using the agents of change in every village. The agents of change were expected to encourage people to do healthy lifestyles such as not smoking, eating healthy food, and increasing physical activity. The agents of change selected from a community leader or health cadres. This model had implemented in 8 Indonesia regencies (Tasikmalaya, Madiun, Banjarmasin, Palembang, Sukabumi, Blitar, Barito Kuala, and Ogan Ilir) in 2015 (Rachmawati et al, 2015, p.33).

The NCDs prevention model had developed from the adoption of the Community-Led Total Sanitation (CLTS) program. CLTS program used the triggering method to change community behavior in hygiene and sanitation behavior. In the NCDs prevention model, the triggering method has used to raise awareness on NCDs risk. The NCDs community-based prevention model had developed based on The Health belief model theory from Rosenstock and The Pre Caution Adoption Process Model from Weinstein et al. (Rachmawati et al, 2015, p.18).

The result of the monitoring and evaluation of NCDs prevention model in Benda Village, Sukabumi regency, was far from success. The health behavior change was hard to achieve, not all the agents of change could do healthy lifestyles to prevent NCDs. This model had not noticed the social factor that can influence the success of the program. Nowadays medical world must be considered social elements such as social class, neighborhood condition, and social factor. The medical world has not viewed only physical terms (Porter 1997 in Cockerham, 2007, p.8).

\section{Methods}

The objective of this article is to make a critical analysis of the NCDs Prevention Model theoretical based. The article is also criticizing the community empowerment implementation in the NCDs model in the location of the study.

This article had used data from qualitative research, which have conducted in 2017. An in-depth interview was the primary method to gain data. Agents of change and the people around them like their family, their neighborhood, community leader, and village officer government had interviewed in this research. Besides indepth-interview, direct observation was another method to gain data. From direct observation, the researcher had observed about healthy behavior among the agents of change (AoC). The secondary data also used from Benda Village local government and other sources.

The data have analyzed using spiral data analysis. Data have categorized into several themes. After that, the data have interpreted and visualized in narrative forms.

\section{The Description of NCDs Prevention Model}

The NCDs Prevention model has adopted the triggering method from Community-Lead Total Sanitation Program. The goal of the triggering method is to develop people's awareness of NCDs risk. As a result, they will change their risk behavior and will do healthy lifestyles. The NCDs prevention model develops based on The Health Belief Model (HBM) theory and The Precaution of Adoption Process Model (PAPM) theory. Below is the scheme of NCDs community-based prevention model : 


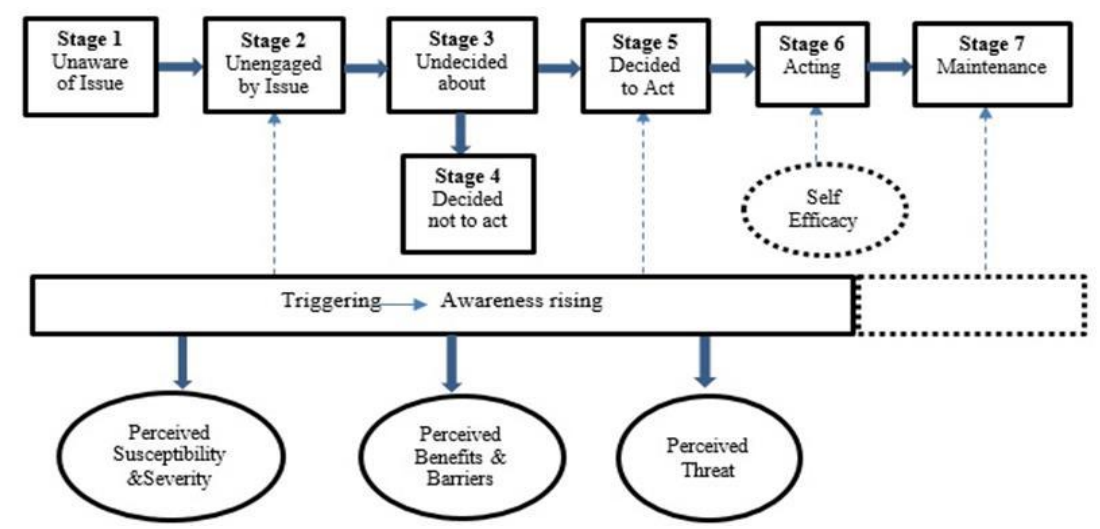

Figure 1.NCDs Community - Based Prevention Model Theoretical

Sources : (Rachmawaty et al. 2015, p.19)

There are seven stages of individual behavior change in the P2TMBM model. In the first stage, someone does not aware of NCDs risk. In the second stage, someone has not unengaged about NCDs issue. In this stage, the intervention started to begin with triggering method to increase the individual awareness about NCDs risk. According to HBM theory, in the first and second stage has been affected by their perceived susceptibility and severity. In the third stage, after triggering action, someone had not decided their next step towards NCDs' problem yet.

Then, in the fourth stage, someone had decided not to act to prevent NCDs risk. Their decision has been affected by their perceived benefits and barriers to taking action in NCDs' problem. Next, in the fifth stage, is the stage where someone is starting to decide to act about NCDs issue. In the sixth stage, someone does some action to overcome NCDs risk, which self-efficacy. In the fifth and sixth stages were influenced by their perceived threat about NCDs. Finally, in the seventh stage, someone will maintain their action to prevent NCDs risk.

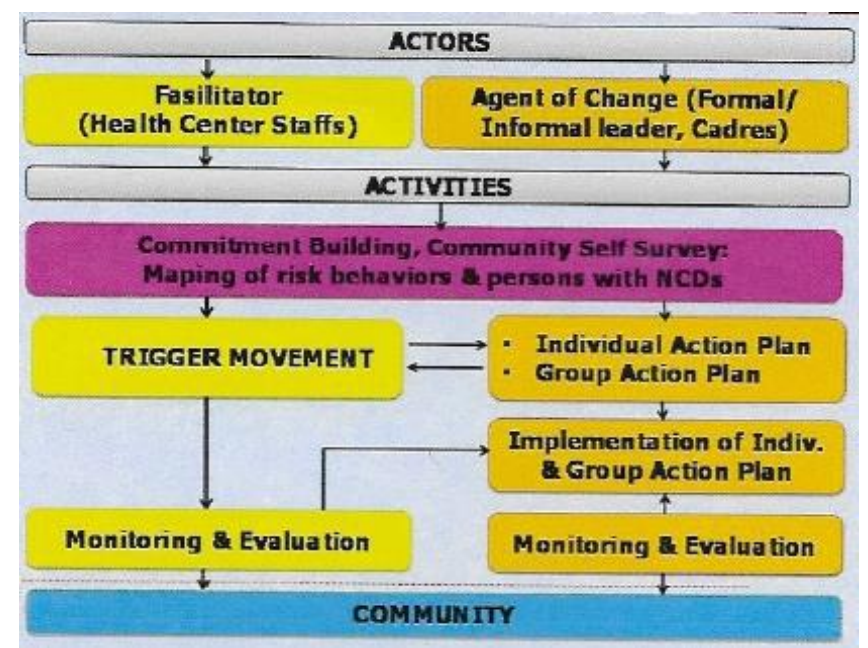

Figure 2. The NCDs Community-Based Prevention Model Scheme

Sources : (Rachmawaty et al., 2015, p.26).

The actors from this model are the local facilitator who was from Health Center staff and the agent of change. For the first step, the local facilitator gave training to the agent of change. The training held for three days which consist of commitment building and community self-survey. In self-survey, the agents of change mapping the NCDs risk behavior and persons with NCDs in their communities. After that, the facilitator gave trigger 
movement using discussion methods and materials such as pictures and videos that can raise fear or threat to NCDs. At the end of the training, the agents of change were asked to formulate individual and group action plans to prevent NCDs. After the training, the agents of change implementing their individual and group action plan. Then, after three months, the researcher came again to the village for monitoring and evaluation.

\section{The Critique of NCDs Community-Based Prevention Model Theoretical Based}

NCDs community-based prevention model has formulated from The Health Belief Model (HBM) theory and The Precaution Adoption Process Model theory. Both of these theories too much focus on individual behavior based on psychological theory.

Health behavior interventions are based on discipline that focuses on individual behavior such as psychology, which related to intraindividual concept and economy in rationality and utilization concept. Consequently, in health behavior intervention, more focus on personal behavior changes than social groups, communities, and culture. The effectivity of health behavior intervention began to question. Hence, health interventions should take into account relational aspects between people and their social environment (Holman et al., 2018, p.390).

In the most social psychological theory in health, the social context aspects had not considered yet. Health Belief Model theory viewed health behavior as an individual action and independent product and has not influenced by social relation that attached to rules, values, norms, and social structure. Individual

health behavior needs to understand by looking at the influence of the social context (Burke, et al, 2009, p.60). In health promotion and disease prevention programs, it is necessary to understand the dialectics between social context and the individual (Kidnemariam, 2011, p.170).

Nevertheless, the NCDs prevention model has not been considered the influence of social context yet. This model too much focuses on individual behavior change without looking at the social context. As a result, this model did not pay attention to the factors outside the individual that can affect the individual to do a healthy lifestyle to reduce the risk of NCDs. In Benda Village's social context, the religious leader has a strong influence on the community. However, many religious leaders are a smoker.

"Here all the people in the village more respectful to the Kyai (religious leader) while almost all the Kyai are a heavy smoker" (Statement from informant A).

The social context example is family interaction, neighborhood and community interaction, social support between friends, co-workers, and the member of a community (Burke, et al., 2009, p.66). Most agents of change in Benda Village give information about NCDs to their families. They also have motivated their family to do healthy lifestyle behavior to prevent NCDs. They have close relationships with their families. Therefore they paid more attention to their family health in the first place. The agents of change also feel more comfortable motivating their own families than other people because their families more trust them.

Moreover, in Health Belief Model theory stated that health behavior depends on individual perceived susceptibility and severity, perceived benefits, and barriers in health behavior. HBM theory has criticized could not predict the long term behavior. (Linke, Sarah E, et al, 2014, p.5).

NCDs community-based prevention model has implemented in Benda village, Sukabumi regency, in 2015. In line with the HBM theory critique, the NCDs prevention model could not make long term effects. The effect of this model only happened in the short term period. In smoking behavior, some agents of change feel fear and threat when they saw the video about the smoking effects, and some of them promise to quit smoke. Nevertheless, after two years, they have forgotten they promise and still smoking. 
"After The Agent of Change training, I still remember the negative effect of smoking, and I thought to stop or to reduce smoking. But now, after two years, I have forgotten the danger of smoking and back to smoking again" (Statement from informant F).

Another theory used in this model is the theory of The Precaution Adoption Process Model (PAPM) from Weinstein et.al. This theory was highlighted individual risk perception and has an assumption about the stages of behavior change. Nevertheless, PAPM theory could not explain how behavior changes on a personal level become changes at the societal level. The results of this study showed that some agents of change had changed their behavior, but the changes in societal level had not occurred.

NCDs, community prevention model, delineated that health behavior change will happen when agents of change had implemented their individual and group action plan. In the NCDs theoretical model only explain the stages when the AoC training held. The steps explain from the beginning when individuals unaware of their risk behavior until they decided and have self-efficacy to change their health behavior. However, in the implementation, there is no definite indicator that can be used to measure the success of the intervention.

After the training, the agents of change has a goal to give information to other people about the risk of NCDs and how to prevent NCDs. One of the barriers for agents of change to motivate people to change their risky behavior is about trust between them with Benda villagers. Some of the Benda villagers did not trust the agents of change because not all agents of change have a social position in Benda village.

"Benda villager doubts my position, why I told them the dangerous effect of smoking. They did not believe the information that I have told them. They said that if smoking is harmful, why the government still allowing cigarette factories" (Statement from Informant $\mathrm{N}$ )

Benda villagers also distrust the agents of change because none of the agents of change are health workers. Benda villagers stated that people who are capable of explaining about NCDs are only a health worker. As a result, people assume that the agents of change should not give them information about NCDs.

\section{The Critique of The Community Empowerment Implementation in NCDs community-based prevention model in Benda Village}

NCDs community-based prevention model used community empowerment methods to make changes in healthy lifestyle behavior in communities. The agents of change were expected can motivate other people to do healthy lifestyles to prevent NCDs.

Wallerstein (1992) argued that empowerment is the process of social action to increase people's participation, organization, and communities, which has a goal to enhance individual control and community (Rissel, 1994, p.41).

Empowerment is a crucial principle in community development. Empowerment is not only a principle but also one of the ultimate goals of community development. As Ife (2002) argues, empowerment should be an aim of all community development. The meaning of empowerment is giving people the power to be able to make decisions, choices, and directions that will lead to an improvement in their lives. People in the community have the power to manage their own development (Waweru, 2015, p.64).

The meaning of community empowerment is about the collective decisions made by community members collectively, which affect their lives and health. The participation of community members is a dynamic process that sometimes can be strong or less. Building social cohesion, increasing critical awareness, and collective action is the way to empower the community to solve inequalities in health. The main argument is that 
supportive, and healthier environments could realize if communities can identify health and social issues and implement appropriate solutions. The sustainability of social action could reach with community organizing and capacity building, mutual aid based on strong social networks, and independent community-led activities. (Public Health England, 2015, p.12).

Based on the meaning of community empowerment, we can conclude that to empower people in society; they must have power, control, and make their own decision to make their life better. In the implementation of NCDs community-based prevention model in Benda village, not all agents of change have power and resources to influence other community members to do healthy lifestyles. The agents of change also did not make their own decision to involve in this model.

NCDs prevention model in Benda Village had implemented without the formulation of community needs that defined by them. Before the implementation of this model, there is no community assessment conducted to know the needs of communities. Based on the result of an in-depth interview, not all agents of change stated that NCDs are problems for them. As a result, they did not prioritize NCDs as problems that need to solve soon.

"NCDs is not a problem in Benda Village. If it is a problem, it means there is already a disease in Benda Village, which has a big effect on communities" (Statement from Informant AN).

Community development could be categorized using a bottom-up approach if developed based on local knowledge, community needs, and community expertise (Ife, 2009, p.30). However, the implementation of NCDs community-based prevention model in Benda village not suitable with the bottom-up approach. This model initiative derived from the National Institute of Health Research and Development, Ministry of Health of Indonesia. Benda villagers did not ask first whether they need the program or not. The community member initiative will emerge if they think that non-communicable diseases were a problem for them. Benda villager did not consider NCDs as a problem that needs severe immediate action to overcome. In this model, the meaning of community-based only related to the involvement of community members as agents of change.

Moreover, the improvements in health outcomes can be achieved with community-based empowerment. Some evidence delineates that community action has a relation with health outcomes. For example, in Surfers Paradise in Australia, community action led to increased regulation of licensed alcohol premises and the implementation of policies and a code of practice for bar staff and as consequence-reduced alcohol-related violence. Community action at Piha in New Zealand led to bans on public drinking, resulting in fewer injuries and incidents of crime and an improved sense of well-being (Laverack, 2006, p.114).

The implementation of the NCDs community-based prevention model in Benda village could not push Benda villagers to make a collective decision to prevent NCDs. Benda villagers also had not taken action yet to support the sustainability of this model. This model hard to sustain due to the lack of mutual aid based on strong social networks. The agents of change had chosen not by the social networks that they had in their communities. Not all the agents of change have a social position in their communities, so not all of them have the power to influence their communities. Moreover, not all the agents of change stated that NCDs are a big problem for them. This situation made the agents of change could not identify health problems and suitable solutions to prevent NCDs.

Another principle of community development is the existence of community participation. Community participation is both a means and ends in community development. Participation as a means implies the use of participation to achieve some predetermined goal or objective. The stress is on making the objective and not so much on the act of participation itself. Participation as an end attempts to empower people. The attempt is to ensure the increased role of people in development initiatives (Kuruvilla and Sathyamurthy, 2015, p.17). 
In the implementation of NCDs prevention model, community participation only as a means not as ends. Community participation uses to achieve specific behavior change in NCDs. The end of this program not to viewed participation as a long-term process.

Studies about cardiovascular diseases in the African-America community in Michigan USA showed that cultural factors, community participation, and community capacity could affect the acceptability and the success of this program (Williams, 2000, p.207).

Community health development is the process, whereas the community can identify the factors which affect their health status. The communities also can access all resources to enhance their capacity so that they can get the result from the identification of their needs. The goal of the communities is to develop local ability to solve their health problem with broadening perspectives such as community development and community organizing (Felix et al., 2010, p.10).

The resulting study from Williams and Felix et al. showed that the community development program in health could make changes in society if there are community participation and community development in communities. Community participation is the main factor in the community development program. Community participation can make communities solve their problem because they can identify the cause of the problem that they faced. Nevertheless, sometimes, communities have limited resources. Therefore a community development program must be carried out.

\section{Discussion}

The holistic model has seen diseases not only from one factor but from many factors such as a product from social, economy, behavior, biology, ecology, politic, and cultural factor. By using a holistic approach, NCDs will be view as a social product not only as individual behavior (Kidanemariam, 2011, p.169). Therefore, the design of the NCDs prevention model can modify by using a holistic approach which combined multidisciplinary approach such as medical, behavior, and social structure.

However, the results of the implementation of the NCDs prevention model in Benda Village showed that the behavior change in the community-level had not reached yet. The behavior change only happened at an individual level, and not all agents of change can change their NCDs risk behavior, especially in smoking behavior. NCDs risk behavior such as smoking is typical behavior and not seen as a behavior that breaks the social norms.

Moreover, to make an effective intervention on NCDs should consist of a combined level of intervention between individual and societal level. The contextual specificities, such as social capital or social networks, can contribute to the success of NCDs' health intervention. The health intervention of NCDs must be exploring private sources of support and collective processes with community involvement (Schroeders et al, 2017, p.18).

The implementation of the NCDs prevention model in Benda Village had not successful yet. One of the factors that contribute to the result is that this model had implemented without regard to social contexts, such as social networks. If the NCDs prevention model implementation using social networks, the behavior changes will happen not only on the individual level but also at the societal level. By using social networks, community awareness about the risk of NCDs will increase. People will realize that they have an NCDs risk from other people in their social networks circle. The existence of social networks in the community also can spread the healthy lifestyle behavior that can prevent NCDs.

Health intervention programs should base on a relational approach that consists of interaction between someone with their social communities. They also must have an identity construction that they are part of those 
communities. To make a health intervention program is necessary to take account of affective relational. Effective health intervention can achieve with social networks identification. Strong social networks with affective relational are required to reach health behavior change in health intervention. Strong social networks can push positive health behavior with social control mechanisms between social networks members. (Mulvaney-Day dan Womack, 2009, p.20).

In Benda village, the agents of change did not choose based on their affiliation in social groups such as religious groups or youth groups. Not all agents of change were a leader in communities. So, only some agents of change have the power to influence communities. When the agents of change is a community leader who has power in the communities, they will trust by community members. Trust from communities would make it easier for the agents of change to influence community members to do a healthy lifestyle.

One of the vital success of community empowerment is social capital in the community. Social capital can be the base of social intervention and can make the sustainability of social intervention (Kilpatrick et al., 2003, p.424). To redesign the NCDs community-based prevention model need to develop based on community needs. The communities must decide by themselves that NCDs are problems and need to solve as soon as possible. Then, the new design of this model must consider the existence of social capital in communities.

Based on the research result from M. Hosey et al. (2016), the success of NCDs collaborative program in Pacific Island, United States has a focus on local knowledge, cultural strength, and traditional action. Besides, the environmental learning season, which involved local trainer, facilitating peer social networks, and communication between team members, also have contributed to the success of the program. Nevertheless, the NCDs prevention model in Benda village had not been implemented based on local knowledge and cultural strength. Benda village communities have a robust Islamic religious value. The sustainability of this model can reach by including the values of Islamic religion in the redesigned model.

Karelia NCDs project in Finlandia held for 25 years (1972-1997). The strong recommendation from the Karelia project is the prevention of the diseases in communities must have take account in principle and rules in program planning, implementation, and evaluation. A deep understanding of communities and collaboration with various community organizations also needed to make a successful intervention program (Puska, 2002, p.3).

A deep understanding of Benda village had not done before the intervention program after intervention collaboration between various community organizations in Benda village had not established yet. Full participation of Benda villagers had not occurred yet because not all of the agents of change did not have enough power to influence communities.

The changes in the social and physical environment must have been done to support healthy lifestyles - this recommendation based on the success of the Karelia health community program in Finlandia. The implementation of a community-based prevention model in Benda village had not done yet. Changes in the social environment must be happening to build healthy lifestyles norms among communities. Besides, changes in the physical environment also needed to provide more facilities to support healthy lifestyles.

\section{Conclusion}

In conclusion, the NCDs prevention model must consider the social context to achieve healthy lifestyle changes in the community. NCDs community-based prevention model scheme needs to be modified, which considers the influence of social context on individual behavior change. The modify NCDs community-based prevention model focus on not only individual behavior but also on the social environments that can make people do healthy lifestyles. The agents of change have a significant role in the implementation of this model. Hence, the 
agents of change must be a local leader that has access to the social network in the community. If the agents of change have a strong social network, they can mobilize their network to support the NCDs prevention model. The agents must have affiliation with a social group in the community, so the people in the community will trust the agents of change. Moreover, a holistic and integrated approach can be utilized to improve the design of the NCDs prevention model.

\section{Acknowledgments}

The author would like to thank the National Institute of Health Research and Development, who support the author to participate in the International Conference on Social Sciences 2019. The author also gives thanks to Dr. Linda Darmajanti Ibrahim, Ph.D., who became a supervisor in this study.

\section{References}

Burke, Nancy J, et al., 2009, Theorizing Social Context: Rethinking Behavioral Theory. Health Education and Behavior Vol 36 (Suppl. 1) October, pp. 55-70.

Cockerham, Wiliam C, 2007, Social Causes of Health and Disease. Cambridge UK: Polity Press.

Data Center and Information Ministry of Health of Indonesia, 2012, Buletin of Non-Communicable Diseases, Date of Access : 06 August 2019. http://www.pusdatin.kemkes.go.id

Felix, Michael R.J, et al., 2010, Community Health Development: A Strategy for Reinventing America's Health Care System One Community at a Time. Journal Primary Prevent Vol 31, pp. 9-19.

Holman, Daniel et al., 2018, How do health behavior interventions take account of social context? A literature trend and co-citation analysis. Health Journal Vol. 22(4), pp. 389-410

Ife, Jim, 2009, Human Rights from Below: Achieving Rights Through Community Development. New York: Cambridge University Press.

Institute for Health Metrics and Evaluation (IHME), Indonesia Global Burden of Disease Data, Date of Access:02/08/2019. http://www.vishub.healthdata.org/gbd-compare.

Kilpatrick, Sue, et al., 2003, Social Capital: An Analytical Tool for Exploring Lifelong Learning and Community Development. British Educational Research Journal, Vol. 29. No.3, pp. 417-433.

Kidanemariam, Adnemariam, 2011, Rethinking Health Promotion and Disease Prevention in Africa: The Quest for an Integrated Model. Journal of Third World Studies: Fall 2011: 28, 2, pp.161-178.

Kompas. The Strengthening of Posbindu PTM, Date of Acccess: 15/08/2019. http://www.kompas.com

Kuruvilla, Chithra and Sathyamurthy, Dr. K, 2015, Community Participation Towards Effective Social Work Practice. Indian Journal of Applied Research, Volume 5, Issue 12, pp.16-18.

Laverack, Glenn, 2006, Improving Health Outcomes through Community Empowerment: A Review of the Literature. Journal of Health Population and Nutrition, Vol. 24(1), pp.113-120.

Linke, Sarah E, et al., 2014, Applying Psychological Theories to Promote Healthy Lifestyles. American Journal of Lifestyle Medicine, 8 (1), pp.4-14.

M. Hosey, Gwendolyn, et al., 2016. U.S. Associated Pacific Islands Health Care Teams Chart a Course for Improved Health Systems: Implementation and Evaluation of a Noncommunicable Disease Collaborative Model. Journal of Health Care for the Poor and Underserved, Vol. 27, pp. 19-38.

Mack, Melany; Uken, Ron; Powers, Jane, 2006, People Improving the Community's Health Workers as Agents of Change. Journal of Health Care for The Poor and Underserved Feb 2006, pp.16-25.

National Institute of Health Research and Development (NIHRD), Ministry of Health of Indonesia, 2018, Basic Health Survey Report.

Public Health, England, 2015, A guide to community-centered approaches for health and well-being (Full Report), pp. 1-48.

Puska, Pekka, 2002, Successful prevention of non-communicable diseases: 25-year experiences with North Karelia Project in Finland. Public Health Medicine Volume 4(1), pp. 5-7. 
Rachmawati, Tety, et al., 2015, National Institute of Health Research and Development, Ministry of Health of Indonesia. Operational Research to Develop Models for the Potential of Community Empowerment in Efforts to Control NCDs Research Report, pp. 1-166.

Rissel, Christopher, 1994, Empowerment: the holy grail of health promotion? Health Promotion International Journal Vol. 9 No.1, pp. 39-47.

SchroÈders J et al., 2017, How is Indonesia coping with its epidemic of chronic non-communicable diseases? A systematic review with meta-analysis. PLoS ONE 12(6), pp. 1-31.

Williams, Karen Patricia, 2000, Community Development's Role in Cardiovascular Disease Prevention Projects for African Americans. Sociological Practice : A Journal of Clinical and Applied Sociology Vol 2, No. 3, pp. 205-219.

Waweru, Rebecca, 2015, Authentic Community Development: Principles and Fundamentals. International Journal of Humanities \& Social Science Studies (IJHSSS), Volume-I, Issue-V, March 2015, pp.64-70. 